\title{
Short communication: Pure-breeding with sexed semen and crossbreeding with semen from double-muscled sires to improve beef production from dairy herds: Weight and value of calves
}

\author{
Giovanni Bittante, ${ }^{1} \odot$ Riccardo Negrini, ${ }^{2,3}$ Matteo Bergamaschi, ${ }^{4} \oplus$ Alessio Cecchinato, ${ }^{1 *} \odot$ \\ and Hugo Toledo-Alvarado ${ }^{5}$ \\ ${ }^{1}$ Department of Agronomy, Food, Natural Resources, Animals and Environment (DAFNAE), University of Padova (Padua), \\ 35020 Legnaro (PD), Italy \\ ${ }^{2}$ Department of Animal Science, Food and Nutrition (DIANA), Catholic University, 29122 Piacenza, Italy \\ ${ }^{3}$ Italian Association of Breeders (AIA), 00161 Rome, Italy \\ ${ }^{4}$ Department of Animal Science, North Carolina State University, Raleigh 27695 \\ ${ }^{5}$ Department of Genetics and Biostatistics, National Autonomous University of Mexico, Ciudad Universitaria, 04510, Mexico City, Mexico
}

\section{ABSTRACT}

The use of sexed semen to produce purebred replacement heifers allows a large proportion of dairy cows to be mated to double-muscled sires and for quantitative and qualitative improvements to be made to beef production from dairy herds. A survey of 1,285 crossbred calves showed that they are destined not only for veal production (like purebred dairy calves) but also for beef production. Crossbred calves obtained from Belgian Blue sires (sold on average at $34 \mathrm{~d}$ of age and $64 \mathrm{~kg}$ of weight) had a higher market value (€363/calf) than those obtained from double-muscled INRA 95 sires (€297/calf, used for veal production) and from Limousin sires (€216/calf for veal and €271/ calf for beef production). As a sire breed, Simmental did not differ significantly from Belgian Blue, but as a dam breed, the crossbred calves fetched a higher price $(€ 5.11 / \mathrm{kg})$ than when Holstein was the dam breed $(€ 4.50 / \mathrm{kg})$. Compared with heifer calves, crossbred bull calves at sale were younger (34.1 vs. $37.2 \mathrm{~d}$ ) and heavier (64.0 vs. $62.6 \mathrm{~kg}$ of live weight), fetched a higher price (€5.13 vs. €4.99/kg), and had a greater value (€328 vs. $€ 312 /$ calf). As the value of purebred dairy calves was about $€ 80$ to $€ 100 /$ calf, we are able to confirm that the combined use of sexed semen for pure-breeding and conventional beef semen for terminal crossbreeding can increase the income from dairy farms, especially when the sires are double-muscled beef bulls.

Key words: X-sorted semen, calf price, calf value, beef breed, dairy breed

Received December 4, 2019.

Accepted February 4, 2020.

*Corresponding author: alessio.cecchinato@unipd.it

\section{Short Communication}

The use of sexed semen by dairy farmers has increased in recent years due to improved fertility rates and a reduction in cost (Hohenboken, 1999). It is now used not only to increase production of replacement females (Ettema and Østergaard, 2015) but also to raise farm income by increasing the number of dairy cows for terminal crossbreeding with beef sires (Ettema et al., 2017). A large project carried out in the Veneto region (northeastern Italy) showed that the fertility of dairy heifers and cows when inseminated with sexed semen of the same breed is not significantly lower than when inseminated with conventional unsorted semen (Bittante et al., 2020). In contrast, crossbreeding with either dairy or beef semen significantly improved the conception rate. The result is that combining the use of sexed semen, mainly on heifers, to produce purebred replacement heifers with the use of conventional beef semen to produce crossbred calves destined for meat production does not have detrimental effects on the reproduction efficiency of the dairy herd (Bittante et al., 2020).

In recent decades, there has been a constant genetic evolution in both dairy and beef breeds, necessitating the verification and updating of previous information on the market value of crossbred calves. Moreover, beef $\times$ dairy crossbred calves are mainly used for veal production, but the increased distribution and improvement of double-muscled sires open new prospects for their use for beef production as well. The objective of this study was to analyze the characteristics and price of the crossbred calves, according to their paternal and maternal breeds, sex, and destination, to quantify the potential increase in dairy farm income allowed by the combined use of sexed dairy semen for pure-breeding and of conventional beef semen for terminal crossbreeding. 
A total of 125 dairy farms in the Veneto region (northeastern Italy) were registered in the meetBULL project by the Association of Breeders of Veneto Region (ARAV; Vicenza, Italy). The majority are intensive modern dairy farms using TMR based on corn silage, some dry forage, and concentrates and rearing mainly Holstein-Friesian cows but also Brown Swiss, Simmental, and crossbred cows. The main characteristics of the farms and cows and the results for fertility are described in a previous study (Bittante et al., 2020). Almost all the cows and heifers were inseminated artificially by the farmers. As the project aimed to work under the real conditions of commercial farms, the type, breed, and origin of the semen were not pre-established but were instead determined by the individual farmers. Farmers were advised by ARAV to use sexed semen, especially in heifers, and conventional dairy semen in the cows they judged to be the best for obtaining purebred replacement calves. They were also advised to use beef semen, mainly from double-muscled breeds, in the other cows not needed for replacement. Insemination data (e.g., date, type of semen, breed, pregnancy diagnosis) and calving data (e.g., date, sex, mortality) were obtained from ARAV.

The majority of the beef $x$ dairy calves produced within the project were collected and monitored at the point of sale by a local cooperative (VBA SCA, Vicenza, Italy), which recorded the following data for each crossbred calf: the farm selling the calf, ID number, date of sale, weight, price paid in euros per kilogram, and the fattening center or weaner buying the calf. The calves were weighed using computer-operated scales, which were checked before every weighing session. The age of the calf at sale was calculated from the date of birth, and the total value of the calf was calculated by multiplying its weight by its price per kilogram.

All records with incomplete information were excluded from the statistical analyses. Sick or injured crossbred calves were also discarded. Outliers were detected after preliminary analysis with the model described below, and all data regarding a given trait with a residual value outside the residual standard deviation of the preliminary model interval of $0.00 \pm 3.0$ were excluded. All data were analyzed using PROC MIXED (SAS Institute Inc., Cary, NC) according to the following mixed model:

$$
\begin{gathered}
\mathrm{y}_{\mathrm{ijklmn}}=\mu+\operatorname{Sex}_{\mathrm{i}}+\text { Meat }_{\mathrm{j}}+\text { SireBreed }_{\mathrm{k}}\left(\text { Meat }_{\mathrm{j}}\right) \\
+ \text { DamBreed }_{l}\left(\text { Meat }_{\mathrm{j}}\right)+\text { Farm }_{\mathrm{m}}+\mathrm{e}_{\mathrm{ijklmn}},
\end{gathered}
$$

where $y_{\mathrm{ijklmn}}$ is the trait analyzed; $\mu$ is the overall intercept of the model; $\mathrm{Sex}_{\mathrm{i}}$ is the fixed effect of the ith sex ( $\mathrm{i}=2$ levels: intact males and females); Meat is the fixed effect of the $\mathrm{jth}$ type of meat produced ( $\mathrm{j}=1$ for veal production and 2 for beef production); SireBreed $_{k}\left(\right.$ Meat $\left._{j}\right)$ is the fixed effect of the sire breed within meat type ( $k=1$ to 6$)$; $\operatorname{DamBreed}_{1}\left(\right.$ Meat $\left._{j}\right)$ is the fixed effect of the dam breed within meat type $(1=1$ to 7); Farm $_{\mathrm{m}}$ is the random effect of the farm of birth; and $\mathrm{e}_{\mathrm{ijklmn}}$ is the random residual $\sim N\left(0, \sigma_{e}^{2}\right)$.

The distributions of the dam breeds were strongly unbalanced in favor of Holstein-Friesian and the sire breeds in favor of Belgian Blue, reflecting the market situation and the intensive dairy system in the study area and farmers' preferences. Therefore, we could not include all the sire breed $\times$ dam breed combinations in the model. After some preliminary analyses, we decided to include the effects of sire breed and dam breed nested within meat type and include only observations with counts of at least 18 . The significance of the differences $(P<0.05)$ among the sire breeds within meat type was based on the contrasts between the Belgian Blue, taken as the reference, and the other beef breeds. Similarly, in the case of dam breed, the Holstein-Friesian was taken as the reference and compared with the other dairy breeds.

Of the monitored crossbred calves, $62 \%$ were males, which reflects dairy farmers' preference for retaining heifers to produce meat to supply their own family and fulfilling the demand of small, unspecialized local beef producers. The crossbred calves were sold at an average age of $5 \mathrm{wk}$ and an average weight of $63 \mathrm{~kg}$ (Table 1 ). It is worth noting that in a previous large survey of the characteristics of calves sold at auction in the mountain areas of northeastern Italy (Dal Zotto et al., 2009), the average age of the beef $x$ dairy crossbred calves at sale was lower than in the present study ( 24 vs. 36 d, respectively), but they had similar live weights (67 vs. $63 \mathrm{~kg}$, respectively). This mainly reflects the different attitudes of dairy farmers operating traditional mountain farms and those operating modern farms on the plains regarding the role of crossbreeding and stock calf production in their operations. In traditional mountain dairy systems (small farms, old buildings, low input, low production) in particular, the practice of beef crossing is widespread and does not require the use of sexed semen to fulfill their low replacement needs. In these farms, purebred and crossbred calves destined for sale are fed intensively, often on whole cow milk, which improves the calves' growth rate, conformation, and commercial value. In the intensive specialized dairy farms on the lowlands, like the large majority of those involved in this study, the calves exceeding replacement needs (usually purebred dairy bull calves) are considered marginal to the farm's commercial interests. They are kept together with the purebred heifer calves 
Table 1. Effects of sire and dam breed on the characteristics of calves obtained by dairy farms using sexed semen to produce purebred replacement heifers and beef semen to produce beef $\times$ dairy terminal crossbreds and sold to specialized fatteners for white meat (veal) or red meat (beef) production

\begin{tabular}{|c|c|c|c|c|c|}
\hline \multirow[b]{2}{*}{ Item } & \multirow[b]{2}{*}{ Calves, no. } & \multicolumn{4}{|c|}{ Characteristics at time of sale } \\
\hline & & Age, $d$ & Weight, kg & Price, $€ / \mathrm{kg}$ & Value, $€ /$ head \\
\hline \multicolumn{6}{|l|}{ Sex } \\
\hline Male & 953 & $34.1^{\mathrm{A}}$ & $64.0^{\mathrm{b}}$ & $5.13^{\mathrm{B}}$ & $328^{\mathrm{B}}$ \\
\hline Female & 577 & $37.2^{\mathrm{B}}$ & $62.6^{\mathrm{a}}$ & $4.99^{\mathrm{A}}$ & $312^{\mathrm{A}}$ \\
\hline \multicolumn{6}{|l|}{ Destination } \\
\hline \multicolumn{6}{|l|}{ Veal calves } \\
\hline \multicolumn{6}{|l|}{ Sire breed } \\
\hline Belgian Blue & 736 & 34.1 & 66.7 & 5.39 & 363 \\
\hline INRA 95 & 24 & 31.6 & 62.8 & $4.61^{* *}$ & $297^{* * *}$ \\
\hline Limousin & 57 & 32.6 & $59.4^{* * *}$ & $3.72^{* * *}$ & $216^{* * *}$ \\
\hline Simmental & 19 & 36.3 & 62.2 & 5.01 & 315 \\
\hline \multicolumn{6}{|l|}{ Dam breed } \\
\hline \multicolumn{6}{|l|}{ Sire breed } \\
\hline Belgian Blue & 400 & 34.9 & 65.9 & 5.45 & 362 \\
\hline Limousin & 21 & 37.4 & 62.2 & $4.19^{* * *}$ & $271^{* * *}$ \\
\hline \multicolumn{6}{|l|}{ Dam breed } \\
\hline Holstein-Friesian & 294 & 36.4 & 64.5 & 4.91 & 325 \\
\hline Brown Swiss & 102 & 34.4 & 64.2 & 4.84 & 319 \\
\hline Crossbreds & 31 & 37.7 & 63.4 & 4.70 & 307 \\
\hline Farm variance, ${ }^{1} \%$ & - & 38.0 & 52.2 & 27.9 & 47.8 \\
\hline Root mean squared error & - & 12.9 & 8.1 & 0.82 & 69 \\
\hline
\end{tabular}

${ }^{\mathrm{a}, \mathrm{b}}$ Means within a column with different lowercase superscripts are significantly different $(P<0.05)$.

${ }^{\mathrm{A}, \mathrm{B}}$ Means within a column with different uppercase superscripts are significantly different $(P<0.01)$.

${ }^{1}$ Percentage ratio between farm variance and the sum of farm and residual variances.

${ }^{*} P<0.05 ;{ }^{* *} P<0.01 ;{ }^{* * *} P<0.001$. Asterisks refer to the significance of the contrast between either a sire breed and the Belgian Blue assumed as sire reference or a dam breed and the Holstein-Friesian assumed as dam reference.

destined for replacement and fed a similar diet with restricted quantities of milk replacer and solid feeds. It is worth noting that the variability among the different dairy farms of origin of the calves represents a large proportion of the total variance $(38 \%$ for age at sale and $52 \%$ for the live weight of calves sold; Table 1).

The average price fetched by crossbred calves during the project was $€ 5 / \mathrm{kg}$ of live weight, corresponding to $€ 318 /$ calf (Table 1). These average values are similar to those reported by the Italian Institute of Agricultural and Food Market Services (ISMEA, 2019), which also found that the average value of purebred dairy calves sold in Italy varied in the range of $€ 80$ to $€ 100$. This means that the market value of a beef crossbred calf is 3 to 4 times higher than that of a purebred dairy bull calf and that the value gained by substituting dairy semen with beef semen was about $€ 200$ to $€ 250 /$ cow. The average price and value reported in the previous survey of calves sold at auction in the mountains (about $€ 7.5 /$ $\mathrm{kg}$ and $€ 520 /$ calf) were greater than those found here.
The large difference seems to be due to the more intensive calf feeding regimen in the mountains and the selling of calves through public auctions organized by breeders' cooperatives and not to large price fluctuations over time. In fact, the average market price and value in the mountains (see Kovieh, 2019) are still very similar to those reported in the previous survey.

A different situation is found in northern Europe, where beef $\times$ dairy crossbred calves are in less demand on the local market. In Ireland, 2- to 6-wk-old calves sired by beef bulls fetch $€ 40$ to $€ 100$ more than their purebred dairy counterparts (Mc Hugh et al., 2010). In a simulation designed to explore the economic opportunities arising from the use of sexed semen and beef bull semen in dairy herds under the conditions of Danish dairy farms (not much different from our conditions), Ettema et al. (2017) assumed a value of $€ 80 /$ calf for purebred dairy bull calves sold at 2 wk of age and a value that was not much greater for beef crossbred calves (€133 on average for bull and heifer calves). It is worth 
noting that the variability explained by the calves' farm of origin is also very high for monetary traits $(28 \%$ for price and $48 \%$ for total value), which includes the variability in live weight (Table 1 ). We think this could also reflect different attitudes of farmers toward management and feeding of crossbred calves. Some farmers manage crossbred calves like the purebred heifer calves retained for replacement, whereas others prepare them for the market, giving them more milk replacer.

The difference between bull and heifer calves was found to be $€ 91$ in the Danish simulation (Ettema et al., 2017), €70/calf in the Irish survey (Mc Hugh et al., 2010), €100 in our previous survey in mountain areas (Dal Zotto et al., 2009), and only $€ 16$ in this study. It should be pointed out that females have been much less penalized in mountain areas in recent times (Kovieh, 2019), and it is clear that this also depends on the sire breed of the crossbred calves (Dal Zotto et al., 2009) and the selection objectives of the beef breed. A consequence of this modest price differential between bull and heifer calves is that the use of Y-sorted beef semen to obtain more bull crossbred calves does not seem to compensate for greater semen cost and a possible reduction in cow conception rate.

Both beef breeds and dairy breeds are genetically evolving due to advances in selection methods and objectives with respect to the past (Andersen et al., 1981). In the case of the Belgian Blue, the breed most commonly used in Italy for crossing beef bulls on dairy cows, the main selection objectives are growth rate, muscularity (Coopman et al., 2007), and direct effects on calving ease, an important trait for crossbreeding on dairy cows (Arthur et al., 1988). Maternal effects of calving ease are not selected in Belgian Blue cattle because almost all calves are delivered by cesarean section (Kolkman et al., 2007), so a phenotypic variability for this trait cannot be measured. This is not the case for other double-muscled and conventional breeds. Maternal and direct effects on ease of calving are the major traits included in the selection indices for the Piedmontese breed (Kizilkaya et al., 2003). These different selection objectives are responsible for the different modifications in the productivity and carcass traits of heifers that have led to lower sexual dimorphism in the Belgian breed compared with the Italian breed (Bittante et al., 2018). This may be the main cause of the smaller difference between the values of bull and heifer calves from Belgian Blue sires and dairy cows. Another reason could be the fact that double-muscled crossbred young bulls tend to be very lean and have some difficulty in reaching the fatness scores required by the market. This is not a problem for crossbred heifers, which mature earlier than intact males but later than heifers from conventional beef breeds.
Slightly more than half of the crossbred calves were sold to calf fatteners for white meat (veal) production, whereas the others were destined for red meat (beef) production. One-third of the latter were retained, weaned, and fattened on the dairy farms where they were born, and two-thirds were sold to specialized beef fatteners. The production goal did not affect the age, weight, price, and value of crossbred calves at sale (Table 1).

The dairy farmers involved in the project used mainly Belgian Blue semen to produce crossbred calves because it is well known and is commercially advantageous. However, other beef breeds were also used with dairy cows. Limousin semen was much more frequently used in the past but has been largely replaced by Belgian Blue semen because of the superiority of this breed in terms of weight, price, and especially total value per calf $(+€ 147$ and $+€ 91$ for calves destined for veal and beef production, respectively; Table 1). This difference is similar to that previously reported in the mountain areas (Dal Zotto et al., 2009) but much larger than that reported in the Irish markets (Mc Hugh et al., 2010). Simmental is also sporadically used as a beef breed on Holstein and Brown Swiss cows. Very recently, some farmers have started using another double-muscled breed, the INRA 95. The market value of these crosses was lower than that of the Belgian Blue crossbreds but higher than that of the Limousin crosses, although this could be partly because these crossbreds are not yet well known in the area.

The effect of dam breed on the characteristics of crossbred calves was negligible. Only calves from dualpurpose Simmental cows fetched a higher price than calves from Holsteins (Table 1), confirming the results obtained in the previous survey on mountain areas (Dal Zotto et al., 2009) and the market values of cull dairy cows (Bazzoli et al., 2014; Gallo et al., 2017) and young bulls (Gallo et al., 2014).

Taking into account the effects on fertility (slightly, not significantly, lower for dairy sexed semen and significantly higher for beef cross-breeding) and sex ratio (Bittante et al., 2020), it could be estimated that for every heifer inseminated with sexed semen $(\sim 1.5$ doses/ conception), the number of cows needed for obtaining the replacement could decrease by 0.8 to 0.9 cows that could be destined to beef crossbreeding (2.0-2.5 doses of beef semen instead of 2.5-3.0 doses of dairy semen). The value differential of a crossbred calf compared with that of a male dairy calf in case of use of double-muscled sires in a market appreciating beef from lean, muscular animals could be $€ 200$ to $€ 250 /$ pregnant cow. In conclusion, this study showed that the combined use of sexed dairy semen for pure-breeding and conventional beef semen for crossbreeding could be an effective way 
of increasing the income of dairy farms, especially when the sires are double-muscled breeds.

\section{ACKNOWLEDGMENTS}

The authors thank the Veneto regional government for funding the meetBULL project. Moreover, they thank the Associazione Regionale Allevatori del Veneto (ARAV, Veneto Regional Breeders Association, Vicenza, Italy) and VBA SCA Veneto (Vicenza, Italy) for recording calf data as well as Adriano Toffoli, ARAV director, for collaboration. The authors declare that there are no conflicts of interest.

\section{REFERENCES}

Andersen, B. B., A. De Baerdemaeker, G. Bittante, B. Bonaiti, J. J. Colleau, E. Fimland, J. Jansen, W. H. E. Lewis, R. D. Politiek, G. Seeland, T. J. Teehan, and F. Werkmeister. 1981. Performance testing of bulls in AI: Report of a working group of the commission on cattle. Livest. Prod. Sci. 8:101-119. https://doi.org/10.1016/ 0301-6226(81)90015-4.

Arthur, P. F., M. M. Makarechian, and M. A. Price. 1988. Incidence of dystocia and perinatal calf mortality resulting from reciprocal crossing of double-muscled and normal cattle. Can. Vet. J. 29:163-167.

Bazzoli, I., M. De Marchi, A. Cecchinato, D. P. Berry, and G. Bittante. 2014. Factors associated with age at slaughter and carcass weight, price, and value of dairy cull cows. J. Dairy Sci. 97:1082-1091. https://doi.org/10.3168/jds.2013-6578.

Bittante, G., A. Cecchinato, F. Tagliapietra, R. Verdiglione, A. Simonetto, and S. Schiavon. 2018. Crossbred young bulls and heifers sired by double-muscled Piemontese or Belgian Blue bulls exhibit different effects of sexual dimorphism on fattening performance and muscularity but not on meat quality traits. Meat Sci. 137:2433. https://doi.org/10.1016/j.meatsci.2017.11.004.

Bittante, G., R. Negrini, M. Bergamaschi, A. Cecchinato, and H. O. Toledo-Alvarado. 2020. Pure-breeding with sexed semen and crossbreeding with semen from double-muscled sires to improve beef production from dairy herds: Factors affecting heifer and cow fertility and the sex ratio. J. Dairy Sci. 103:5246-5257. https://doi .org/10.3168/jds.2020-17932.

Coopman, F., A. Krafft, J. Dewulf, A. Van Zeveren, and N. Gengler. 2007. Estimation of phenotypic and genetic parameters for weight gain and weight at fixed ages in the double-muscled Belgian Blue Beef breed using field records. J. Anim. Breed. Genet. 124:20-25.
Dal Zotto, R., M. Penasa, M. De Marchi, M. Cassandro, N. López-Villalobos, and G. Bittante. 2009. Use of crossbreeding with beef bulls in dairy herds: Effect on age, body weight, price, and market value of calves sold at livestock auctions. J. Anim. Sci. 87:3053-3059. https://doi.org/10.2527/jas.2008-1620.

Ettema, J. F., and S. Østergaard. 2015. Short communication: Economics of sex-biased milk production. J. Dairy Sci. 98:1078-1081. https://doi.org/10.3168/jds.2014-8774.

Ettema, J. F., J. R. Thomasen, L. Hjortø, M. Kargo, S. Østergaard, and A. C. Sørensen. 2017. Economic opportunities for using sexed semen and semen of beef bulls in dairy herds. J. Dairy Sci. 100:4161-4171. https://doi.org/10.3168/jds.2016-11333.

Gallo, L., M. De Marchi, and G. Bittante. 2014. A survey on feedlot performance of purebred and crossbred European young bulls and heifers managed under intensive conditions in Veneto, northeast Italy. Ital. J. Anim. Sci. 13:3285. https://doi.org/10.4081/ijas.2014 .3285 .

Gallo, L., E. Sturaro, and G. Bittante. 2017. Body traits, carcass characteristics and price of cull cows as affected by farm type, breed age and calving to culling interval. Animal 11:696-704. https://doi .org/10.1017/S1751731116001592.

Hohenboken, W. D. 1999. Applications of sexed semen in cattle production. Theriogenology 52:1421-1433. https://doi.org/10.1016/ S0093-691X(99)00227-7.

Italian Institute of Agricultural and Food Market Services (ISMEA). 2019. Carne bovina - Prezzi medi all'origine. Accessed May 20, 2019. http://www.ismeamercati.it/analisi-e-studio-filiere -agroalimentari.

Kizilkaya, K., P. Carnier, A. Albera, G. Bittante, and R. J. Tempelman. 2003. Cumulative t-link threshold models for the genetic analysis of calving ease scores. Genet. Sel. Evol. 35:489-512. https: //doi.org/10.1186/1297-9686-35-6-489.

Kolkman, I., S. De Vliegher, G. Hoflack, M. Van Aert, J. Laureyns, D. Lips, A. de Kruif, and G. Opsomer. 2007. Protocol of the caesarean section as performed in daily bovine practice in Belgium. Reprod. Domest. Anim. 42:583-589. https://doi.org/10.1111/j.1439 -0531.2006.00825.x.

Kovieh. 2019. Prezzi asta vitelli/Kälberpreise. Accessed May 20, 2019 https://www.kovieh.com/it/benvenuti-1.html.

Mc Hugh, N., A. G. Fahey, R. D. Evans, and D. P. Berry. 2010. Factors associated with selling price of cattle at livestock marts. Animal 4:1378-1389. https://doi.org/10.1017/S1751731110000297.

\section{ORCIDS}

Giovanni Bittante 눈 https://orcid.org/0000-0001-7137-7049

Matteo Bergamaschi @ https://orcid.org/0000-0002-3983-5019

Alessio Cecchinato () https://orcid.org/0000-0003-3518-720X

Hugo Toledo-Alvarado @ https://orcid.org/0000-0001-7854-1219 